\title{
Contato corporal entre adolescentes através da dança de salão na escola
}

\author{
Nilza Coqueiro Pires de Sousa ${ }^{1}$ \\ Sandro Caramaschi ${ }^{2}$ \\ ${ }^{1}$ Faculdade de Ciências, UNESP - Univ. Estadual Paulista. Campus Bauru, Mestranda \\ do Programa de Pós-Graduação em Psicologia do Desenvolvimento e Aprendizagem, \\ Bauru, SP, Brasil e Bolsista FAPESP \\ ${ }^{2}$ Faculdade de Ciências, UNESP - Univ. Estadual Paulista. Campus Bauru, \\ Departamento de Psicologia, Bauru, SP, Brasil
}

\begin{abstract}
Resumo: A finalidade deste estudo foi identificar a reação e percepção dos adolescentes em relação ao contato corporal bem como as expressões emocionais através da dança de salão. Participaram 42 adolescentes do ensino fundamental estadual do interior do Estado de São Paulo. A coleta de dados foi realizada em grupo através de uma filmagem da aula de dança de salão e aplicação de um questionário referente à vivência. Verificou-se que as experiências de dança propiciam uma maior proximidade corporal e demonstração de afetividade, pois parte dos participantes relatou bem estar, enquanto outros disseram sentir-se envergonhados ao dançar com parceiro do sexo oposto. Conclui-se que é preciso oportunizar mais atividades dançantes na escola relacionadas ao desenvolvimento biopsicossocial, pois a dança de salão pode auxiliar a interação promovendo o contato corporal e dessa forma pode ser um facilitador no processo das relações interpessoais entre os adolescentes.
\end{abstract}

Palavras-chave: Comunicação não verbal. Dança. Adolescente.

\section{Body contact between adolescents through ballroom dancing at school}

Abstract: The objective of this study was to identify the reaction and perception of adolescents in relation to body contact as well as emotional expressions through ballroom dancing. Forty-two adolescents from a public elementary school in the state of São Paulo participated in the study. Data gathering was conducted in groups by filming the ballroom dance class and applying a questionnaire about the experience. The dance experience was observed to provide greater body proximity and demonstration of affection, since part of the participants reported well-being, while others reported being embarrassed by dancing with a partner from the opposite sex. It was concluded that more dance activities related to biopsychosocial development need to be offered at school since ballroom dancing can help in interaction promoting body contact and thus facilitate in the process of interpersonal relations between adolescents.

Key words: Nonverbal communication. Dancing. Adolescent.

\section{Introdução}

A adolescência é uma etapa do desenvolvimento que envolve muitos conflitos, sendo considerada uma fase crítica, cheia de momentos turbulentos e que requer muita atenção e compreensão das pessoas que circundam esse adolescente. A escola faz parte deste universo e dentre as várias possibilidades de conteúdos, enfatizamos que as atividades dançantes podem contribuir para amenizar essa fase de turbulências, pois auxilia 0 desenvolvimento biopsicossiocial.

A dança é uma forma de expressão humana, assim como a pintura, literatura, escultura, entre outras. Ela faz parte da comunicação não-verbal que envolve todas as manifestações de comportamento como os gestos, as expressões de emoções, orientações do corpo, as posturas, a relação de distância entre os indivíduos e, ainda, organização dos objetos no espaço. Está presente no nosso dia-a-dia, mas, muitas vezes, não temos consciência de sua ocorrência e, nem mesmo, de como acontece (KNAPP; HALL, 1999).

Pereira (2007) menciona que aprender a dançar significa também estabelecer novas formas de comunicação corporal, já que a aprendizagem da dança colabora para a expressividade de manifestação do corpo, ou seja, de manifestação do ser.

Dessa forma, a dança é uma das mais poderosas formas de comunicação e expressão, uma forma de linguagem universal e faz parte da cultura corporal da humanidade. Neste estudo enfocaremos o contato corporal através da atividade de dança de salão, entendendo-a como uma manifestação eminentemente social, de identificação de um grupo, integração e forma de 
lazer e ainda que permita o desenvolvimento dos aspectos físicos, psicológicos e sociais.

\section{Adolescência}

A adolescência foi criada historicamente pelo homem, como representação e enquanto fato social e psicológico. É constituída como significado na cultura, na linguagem que permeia as relações sociais. Fatos sociais surgem nas relações e os homens atribuem significados a esses fatos. Definem, criam conceitos que representam esses fatos. São marcas corporais, são necessidades que surgem, são novas formas de vida decorrentes de condições econômicas e fisiológicas, são descobertas científicas, são instrumentos que trazem novas habilidades $\mathrm{e}$ capacidades para o homem (CONTINI; KOLLER; BARROS, 2002).

De acordo com Papalia (2006), a adolescência se caracteriza pela transição da infância para a idade adulta. Seu começo e seu fim não são claramente marcados nas sociedades ocidentais; dura aproximadamente uma década, entre os 11 ou 12 anos e final da segunda década de vida ou início dos 20 anos. As definições legais, sociológicas e psicológicas do ingresso na idade adulta variam. Em algumas culturas não ocidentais, a chegada à "maioridade" é sinalizada por rituais especiais.

$\mathrm{Na}$ adolescência, a aparência dos jovens muda; como resultado dos eventos hormonais da puberdade, adquirem corpos de adultos. Seu pensamento muda; são capazes de pensar em termos abstratos e hipotéticos. Seus sentimentos mudam sobre quase tudo. Todas as áreas de desenvolvimento convergem à medida que os adolescentes confrontam sua principal tarefa: formar uma identidade inclusive uma identidade sexual (PAPALIA, 2006, p. 434).

A transição na adolescência é desencadeada principalmente pelas mudanças físicas da puberdade, mas é acompanhada por outras mudanças cognitivas, por alterações importantes nos padrões de interação com os pares, pelo aumento do rompimento familiar e da depressão (BEE, 2003).

Para Bee (2003) a passagem para as operações formais na adolescência pode contribuir para um aumento no autoquestionamento; as mudanças puberais podem ter efeitos diretos e indiretos sobre os outros desenvolvimentos deste período. Todas as facetas do desenvolvimento são o produto de alguma combinação ou interação de influências internas e externas.

Corroborando com essa perspectiva, Coll, Marchesi e Palacios (2004) enfatizam que todas essas mudanças internas e externas, que guardam uma estreita relação entre si, farão desse período uma importante transição evolutiva de muito interesse para o estudo dos processos de mudança e continuidade no desenvolvimento humano; uma transição entre a maturidade física, social e sexual da idade adulta.

O conceito de identidade na opinião de Coll, Marchesi e Palacios (2004) está estritamente ligado ao autoconceito que depende em grande parte do desenvolvimento cognitivo. A identidade é um fenômeno psicológico bastante complexo de natureza psicossocial. É necessário considerar que essa identidade, apesar de ser uma característica pessoal, é experimentada em um contexto social determinado, em que o sujeito estabelece uma série de relações e experimentam diversos papéis. Cada um desses contextos (família, o grupo com os iguais ou a escola) terá importância e proporcionará informações ao jovem sobre sua imagem, exercendo uma influência diferente, segundo as demandas propostas ao adolescente.

Quanto ao papel de gênero na adolescência, Shaffer (2005) apresenta três aspectos importantes relacionados ao desenvolvimento humano: a dimensão biológica, com a puberdade através da maturidade sexual e da capacidade de reprodução; a dimensão social, com a passagem da infância para a vida adulta através da adoção de papéis adultos e identificação e a dimensão psicológica, através da estruturação de uma identidade definitiva para a subjetividade.

Os papéis de gênero segundo Bee (2003) são um pouco mais amplos do que a maioria dos outros papéis. Podemos pensar em um papel de gênero como o conjunto de comportamentos, atitudes, direitos, deveres e obrigações envolvido no desempenho do papel de "menina", "mulher", "menino" ou "homem". Com a entrada na adolescência, parece que os papéis e estereótipos de gênero voltam a aumentar o caráter estereotipado das condutas $e$ das preferências que mostram meninos e meninas. A partir da consolidação da identidade começam a ser observadas maiores diferenças individuais entre os gêneros (COLL; MARCHESI; PALACIOS, 2004). 


\section{Comunicação não-verbal: Contato Corporal e Movimento}

As investigações científicas sobre o fenômeno da comunicação verbal e não-verbal são de grande importância para a compreensão dos relacionamentos interpessoais. Uma das razões do grande interesse pelos estudos da comunicação não-verbal pode estar provavelmente relacionada à sua importância e representatividade no processo de relacionamento e compreensão mútua entre seres humanos. Esta importância é evidenciada pelo papel que a comunicação não-verbal desempenha no sistema total de comunicação e a sua utilização nas áreas fundamentais da vida cotidiana (KNAPP; HALL, 1999).

A comunicação não-verbal, segundo Knapp e Hall (1999), desempenha várias funções que ajudam o ser humano transmitir e receber mensagens significativas. Desta forma podemos encará-la como o principal meio de comunicação dos aspectos emocionais, como meio primário e privilegiado para assinalar mudanças de atitude nas relações interpessoais. Podemos vê-la também na apresentação do corpo, pois, dá uma imagem de si mesmo ao mundo que o envolve, e principalmente como um apoio e complemento à comunicação verbal. Se nos lembrarmos que toda a comunicação tem um conteúdo e uma relação, podemos esperar que os dois modos de comunicação não só existem lado a lado mas se complementam na transmissão de todas as mensagens. A comunicação não-verbal serve a muitas funções. Pode repetir, substituir, complementar, enfatizar, regular e contradizer as mensagens verbais.

A linguagem do corpo segundo Pease e Pease (2005) é o reflexo do estado emocional da pessoa. Cada gesto ou movimento pode ser uma valiosa fonte de informação sobre a emoção que ela está sentindo num dado momento. $O$ segredo da leitura da linguagem corporal está na capacidade de captar o estado emocional de uma pessoa escutando o que ela diz e observando seus gestos e atitudes. Todo gesto deve ser considerado no contexto em que ocorre.

Neste sentido a dança faz parte do mundo da comunicação não-verbal, expressando e transmitindo muitas informações com diferentes significados. Dessa forma escolhemos aplicar neste estudo a dança de salão que permite entre os participantes um maior contato corporal e consequentemente a utilização de expressões faciais, demonstrando ou mascarando possíveis emoções durante a atividade dançante.
Como destacam Knapp e Hall (1999) a comunicação não-verbal não deve ser estudada como fenômeno isolado, mas como parte inseparável do processo comunicativo total. Contudo, para fins específicos desta pesquisa, enfocaremos duas áreas: a proxêmica ou comportamento territorial enfatizando a percepção do espaço social e pessoal dos participantes e o movimento corporal ou comportamento cinestésico através principalmente do comportamento tátil (contato corporal) e das expressões de emoções que tem como objeto as configurações que revelam estados afetivos.

A proxêmica ou comportamento territorial, de acordo com Hall (1989), é a maneira como nos comportamos territorialmente, pode ser útil na interação social, no controle da densidade populacional, e também fonte de conflito quando o território é disputado ou invadido. Parte de nosso comportamento espacial está ligado à necessidade de delimitar e manter o território. A orientação espacial pessoal é algumas vezes estudada no contexto da distância de conversação e das variações em relação ao sexo, status, papéis sociais, formação cultural, etc.

Hall (1989), Adler e Towne (2002) e Pease e Pease (2005) classificaram o espaço informal, distância ou território pessoal em quatro subcategorias ou zonas de distância em nossa vida cotidiana: íntimo (relacionamento emocional), pessoal (amigos e colegas), social (negócios impessoais) e público (direcionado a uma platéia). Essa escolha segundo Adler e Towne (2002) depende da maneira como nos sentimos em relação à outra pessoa, em relação ao momento, ao contexto da conversa e aos nossos objetivos interpessoais.

O toque segundo Knapp e Hall (1999) é um
aspecto importante na maioria dos
relacionamentos humanos. Desempenha um
papel nos atos de encorajar, expressar ternura,
mostrar apoio emocional e muitas outras coisas.
Algumas dizem que isso reflete um anseio pelo
contato humano e um desejo de restaurar
algumas necessidades táteis não satisfeitas.

Knapp e Hall (1999) enfatizam que

$\mathrm{O}$ ato de tocar funciona como qualquer outra mensagem que enviamos, ele pode suscitar reações negativas ou positivas, dependendo do relacionamento das pessoas e das circunstâncias. Sabemos que, algumas vezes, as pessoas ficam "super tensas", ansiosas e/ou se sentem desconfortáveis quando tocadas; e o toque percebido como inapropriado no relacionamento pode receber reações agressivas, que podem ser na forma de tapas ou socos. A observação diária nos levaria a presumir que algumas pessoas avaliam quase todos os toques de maneira negativa. Em 
alguns casos, esse desprazer com o toque pode estar ligado a experiências precoces (KNAPP; HALL, 1999, p. 232-233).

Montagu (1988) aponta que a pele é o maior órgão humano e tem muita significância, por isso o contato físico tem uma série de aspectos envolvidos no relacionamento humano, que começa muito cedo na interação humana e assim assume um papel de importância no contato corporal durante 0 desenvolvimento, principalmente nas crianças. O contato corporal precisa ter uma autorização e os indivíduos enviam mensagens corporais se aceitam ou não determinado contato. Quando se toca no outro desenvolve um vínculo emocional entre as pessoas.

Mediante o exposto apresentaremos a seguir a dança de salão enfatizando nesse recorte os aspectos afetivos e psicológicos, bem como a contribuição desta atividade para o entendimento das relações interpessoais dos adolescentes.

\section{Dança de Salão na Escola}

Dança é emoção e a emoção é a essência do homem. Não obstante, várias são as formas de movimentos e ritmos codificados para simbolizar a singularidade das emoções humanas. A dança, hoje, retrata as ansiedades, idéias, necessidades e interesses da nossa época, aliadas à forte necessidade do ser humano de extrapolar a sua essência ou transcender a sua existência em evasões positivas e significativas nas circunstâncias de sua vida real (NANNI, 1995).

$\mathrm{Na}$ opinião de Gonçalvez (2006), a utilização da dança nas aulas de Educação Física do Ensino Fundamental, é imprescindível para o desenvolvimento físico, mental, afetivo e social. Por meio da dança, o aluno tem oportunidade de desenvolver sua capacidade expressiva e criadora, consegue adquirir maior domínio dos seus gestos, bem como confiança e segurança em suas atitudes. A dança contribui ainda para 0 desenvolvimento da consciência corporal, bem como para o aprimoramento da noção de tempo e espaço, da consciência rítmica e da educação dos sentidos.

Deutsch (1997) enfatiza que tanto a música ouvida quanto o movimento da dança têm o poder de influenciar fisiológica e psicologicamente o ser humano. Ambos fazem parte do mundo da comunicação não-verbal, podendo alterar o estado afetivo das pessoas modificando, consequentemente, seu estado de ânimo. Ensinando a dança de salão, tanto na escola como para grupos particulares, clubes, academias ou universidades, pode-se interferir em muitos aspectos da personalidade de nossos alunos, atuando, inclusive, nas suas emoções.

A dança de salão de hoje, segundo Ried (2003), é o resultado de décadas ou até centenas de anos de evolução, retratando e adaptando-se às necessidades e características típicas de cada sociedade e época desde a Idade Média até o século XXI. Como consequência dessa evolução, constitui hoje uma prática de atividade física amplamente difundida por todo o mundo, impulsionada pelos mais diversos motivos, entre eles lazer, esporte, e saúde no mais amplo sentido e necessidades sociais.

De acordo com Volp (1994) a dança de salão coloca as pessoas em contato direto com suas novas emoções, devido aos contatos corporais com parceiros do sexo oposto. Essa autora enfatiza que foi apontado que um dos objetivos do homem na vida é dominar a arte do relacionamento, importante na infância, juventude, vida adulta. A dança de salão, na escola, pode facilitar contatos e levar o jovem a enfrentar os problemas do relacionar-se, pois desafia suas aptidões físicas na procura de harmonia com a outra pessoa e o coloca em contato com a sensação e comunicação corporais, muito sutis e profundas nessa idade.

As vantagens de se incluir a dança de salão na escola, além de ampliar o conhecimento que os alunos têm sobre dança e música, é a de ser uma atividade acessível a ambos os sexos, ser uma dança que promove a sociabilidade, o respeito e a disciplina, e se adaptar às habilidades individuais de qualquer pessoa (VOLP; DEUTSCH; SCHWARTZ, 1995).

Segundo Ried (2003) as pesquisas recentes mostraram que a prática de dança de salão pode ser relacionada positivamente com estados emotivos positivos, permitindo a conclusão de que a dança de salão exerce uma influência positiva sobre o estado emocional dos praticantes.

Para Volp (2010) as relações interpessoais são muito trabalhadas na dança de salão e através delas, as intrapessoais. A solução dos problemas motores na situação aos pares, seguindo um determinado ritmo musical e uma trajetória num salão que deve ser respeitosamente compartilhada com outros, coloca os executantes em situações ímpares de enfrentamento consigo mesmo e com seus parceiros (as).

Diante do exposto utilizamos nessa pesquisa dois ritmos aplicados em cursos de dança de salão. O primeiro ritmo classificado como clássico representado pela Valsa, que é uma dança de salão derivada do Landler entre 1770 e 1780, 
popular na Áustria, Baviera e Boêmia, caracterizada pelo compasso ternário da música, pelos passos em que os pés deslizam pelo chão e pelos giros dos pares. O segundo ritmo foi representado pelo Forró, que é designação popular dos bailes com danças populares encontrados no nordeste do Brasil, no entanto este ritmo é dançado em todas as regiões de nosso país (REITAS; BARBOSA, 1998).

Neste sentido, esse trabalho visa compreender e contextualizar o significado do comportamento dos adolescentes por meio da observação da atividade de dança de salão, por entender a necessidade de oportunizar aos adolescentes vivenciar uma atividade dançante que possibilite novos significados, na tentativa de ajudá-los no enfrentamento de possíveis conflitos advindos desta fase, auxiliando-os na compreensão das relações interpessoais, bem como para melhor identificar como esses adolescentes se relacionam com os colegas da escola e ainda como reagem, percebem e enfrentam as novas emoções presentes no contato corporal com parceiros do sexo oposto através de uma prática dançante.

\section{Método}

O presente trabalho se caracteriza por uma pesquisa qualitativa através de um estudo descritivo, bem como de análises quantitativas, de acordo com a natureza dos dados da investigação.

\section{Participantes}

Fizeram parte deste estudo 42 alunos da $7^{\mathrm{a}}$. série do Ensino Fundamental Estadual, com média de idade de 13,48 anos, variando de 13 a 15 anos, sendo 24 participantes do sexo feminino e 18 do sexo masculino.

A pesquisa foi realizada na quadra de uma escola de Ensino Fundamental, na cidade de Bauru, interior de São Paulo, durante as aulas de educação física.

\section{Instrumentos}

Foram utilizados como instrumentos para coleta de dados a filmagem da aula de Dança de Salão e um questionário com 10 questões, contendo perguntas abertas e fechadas, que buscavam obter informações básicas sobre as características gerais dos participantes e verificar a reação e a sensação vivenciadas pelos participantes após o contato corporal através da prática dançante.

\section{Procedimentos}

O projeto de pesquisa foi avaliado pelo Comitê de Ética em Pesquisa da Faculdade de Ciências da Universidade Estadual Paulista - UNESP, Campus Bauru, tendo sido devidamente aprovado em 02 de agosto de 2010 (Processo 736/46/01/10).

Inicialmente foram apresentadas informações gerais sobre a pesquisa bem como a solicitação de anuência dos participantes. Em seguida foi apresentado o termo de consentimento livre e esclarecido, o qual foi lido e assinado pelos participantes.

Considerando a duração da aula, adotamos como critério, ensinar somente os passos básicos da valsa e do forró, por duas razões: primeiro para oportunizar os alunos o contato com um ritmo clássico e um ritmo brasileiro de dança de salão e segundo por acreditarmos que o tempo seria insuficiente para ensinarmos passos mais elaborados e complexos, uma vez que a maioria dos participantes teria a primeira vivência com os ritmos nessa atividade.

Foi realizada a filmagem de uma atividade de Dança de Salão ministrada na aula de Educação Física dos participantes, com aproximadamente 50 minutos. Posteriormente foi aplicado o questionário na sala de aula, onde os participantes tiveram um tempo de aproximadamente 50 minutos para responder todas as questões. As dúvidas foram esclarecidas pela pesquisadora.

\section{Análise dos dados}

Depois dos dados coletados, foram realizadas análises qualitativas referente à observação obtida através da filmagem e análises quantitativas dos questionários, onde as respostas foram tabuladas, categorizadas e submetidas a tratamento estatístico descritivo.

\section{Resultados e Discussão}

A pesquisa foi realizada em dois momentos (filmagem da aula e aplicação do questionário), sendo os dados analisados qualitativa e quantitativamente.

\section{Registro de imagem}

Durante a observação da filmagem pudemos evidenciar que os alunos participavam muito bem da primeira parte da aula, enquanto a professora ministrava os passos básicos de cada ritmo separadamente, ou seja, homens e mulheres aprendendo e desempenhando os seus papéis na dança. Quando se pediu para que formassem pares para dançar o primeiro ritmo: a valsa, aproximadamente $60 \%$ dos participantes esquivou-se e não formaram os pares, muitos sentaram, conversavam com os colegas, outros pediram para ir ao banheiro, beber água. Em 
torno de $40 \%$ formaram casais para dançar a valsa, demorou cerca de 5 minutos para que eles escolhessem seus parceiros, porém percebeu-se que com atitudes muito tímidas e com receio de se aproximar dos parceiros. Nota-se que 0 distanciamento entre o casal dificultou a execução dos movimentos, apesar da maioria dos participantes conviverem e estudarem juntos há muitos anos, esse fato não foi suficiente para que eles se sentissem à vontade para realizar essa tarefa.

Em seguida, a professora pediu que formassem novamente os grupos de meninos e meninas para ensinar o passo básico do forró. Todos também participaram dessa parte da aula, porém quando se explicou como dançar forró com o parceiro e que seria necessário um contato corporal mais próximo, iniciou-se com 8 casais, ou seja, $20 \%$ dos alunos (16) tiveram coragem de formar os pares e $80 \%$ dos alunos mais uma vez sentaram, esquivaram-se e ficaram observando.

Destes $20 \%$ dos casais (8), 4 pares eram formados por meninas que dançaram juntas. A professora deixou os alunos à vontade para que eles decidissem formar ou não os pares, para que pudessem partir dos próprios alunos a possibilidade de ficar ou não em contato corporal com o parceiro do sexo oposto.

Podemos elencar alguns motivos que podem justificar a rejeição de alguns alunos em formar os pares. Um deles pode estar associado com a experiência dançante restrita dos alunos, na qual a maioria dos participantes não teve ou tem pouca vivência com os ritmos de dança de salão. Alguns alunos vivenciam ritmos dançados sem contato corporal presentes no cotidiano dos adolescentes, onde na maioria das vezes se dança sozinho ou em grupos, mas sempre individualmente.

Outro motivo pode ser atribuído à timidez, por ser uma novidade para muitos, o medo de errar e pisar no pé do parceiro pode dificultar a disponibilidade de dançar com outra pessoa. Outra justificativa pode ser atribuída a intensas mudanças que ocorrem com o adolescente nesse período da vida, pois segundo Aberastury e Knobel (1981) o adolescente nesta fase encontra o universo social e cultural a lhe exigir mudanças, para as quais muitas vezes não está preparado, com isso, apresenta-se uma crise, a qual o adolescente terá que ultrapassar, utilizando-se de estratégias adequadas para alcançar a maturidade com êxito.

\section{Questionário}

A partir da aplicação do questionário os resultados foram tabulados e analisados, fornecendo informações sobre o contexto de festas que os adolescentes freqüentam; se costumam dançar e o que dançam nestas festas; com quem e porque dançam; como se sentiram ao dançar com os colegas do sexo oposto e se consideram importante saber dançar.

Em relação ao tipo de festas que os participantes costumam frequentar, 33\% alunos mencionaram as festas de aniversário; 23\% relataram festas em geral (familiares, fantasia, com amigos, debutantes, escola, teen, intruso, de vila); $14 \%$ disseram frequentar churrascos; $13 \%$ baladas; $8 \%$ casamentos; $6 \%$ outros e $3 \%$ responderam não freqüentar festas.

Destas respostas, os dados mais relevantes comparativamente em relação ao gênero, se referem à participação em baladas, na qual 9\% do gênero feminino costumam frequentar esse tipo de festa enquanto $17 \%$ do masculino; $12 \%$ do gênero feminino participam de festas de casamento enquanto só $3 \%$ do masculino; $26 \%$ do gênero feminino participam de festas em geral enquanto $17 \%$ do masculino; e somente $9 \%$ dos participantes masculinos mencionaram não frequentar nenhum tipo de festa.

No tocante a essa questão podemos evidenciar que os adolescentes deste estudo ainda estão restritos a um pequeno grupo social, que tem nas festas de aniversário de seus familiares e alguns amigos a maior parte da sua interação social, o que pode acarretar um número reduzido de relações sociais interpessoais, bem como a pouca vivência de ritmos e estilos de dança presentes nestas festas.

Em relação à comparação entre gêneros, nota-se que o masculino participa mais de baladas, isso pode ocorrer porque os meninos ainda têm mais liberdade por parte dos pais para saírem de casa, uma vez que este tipo de festa começa muito tarde. Essas diferenças podem ser explicadas claramente pelos processos de socialização, que, a partir da puberdade, tendem a ampliar o leque de possibilidades e de experiências que são oferecidas ao menino (chegar mais tarde em casa, pegar o carro dos pais ou sair de férias com os amigos) e são restringidas para a menina ( $\underline{\mathrm{COLL}}$; MARCHESI; PALACIOS, 2004). Porém o gênero masculino tem pouca participação em festas de casamento e uma pequena parte deles não costumam freqüentar festas.

A respeito da questão sobre se os alunos costumam dançar nas festas que eles frequentam (Figura 1), parece esclarecer a dificuldade que os participantes tiveram em realizar a atividade da aula de dança de salão observada na filmagem, 
pois mesmo frequentando festas, $43 \%$ dos participantes responderam dançar somente às vezes, raramente e nunca, o que demonstra a pouca vivência com a dança e nesta pesquisa especificamente com os ritmos de dança de salão.

De acordo com os dados apresentados na Figura 1 parece ficar evidente que o gênero feminino dança com muito mais frequência do que o gênero masculino. Os dados revelam que a baixa participação dos alunos quando solicitado pela professora em formar os pares, principalmente do sexo masculino (67\%), se deve ao fato de dançarem somente às vezes, raramente e nunca nestas festas.

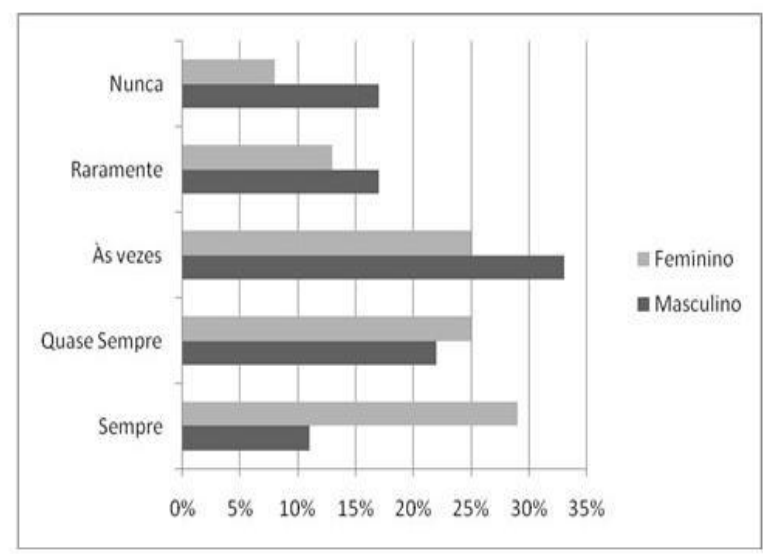

Figura 1. Questão sobre se os participantes costumam dançar nas festas, com possibilidade de assinalar uma única alternativa.

Geralmente os ritmos musicais tocados nestas festas são relacionados a ritmos eletrônicos como "dance", "tecno", "house", etc, onde os adolescentes costumam dançar individualmente, o que resulta uma falta de experiência dançante com os ritmos de dança de salão ministrados nesta pesquisa e assim uma maior dificuldade de aproximação com receio de errar e se expor frente aos demais colegas da escola.

Considerando-se os parceiros de dança (Figura 2), os achados mais significativos desta questão, destacamos que somente $8 \%$ do gênero feminino mencionaram dançar com parceiro amoroso (namorado, ficante) enquanto $15 \%$ do masculino. Apenas $4 \%$ das meninas relataram dançar com desconhecido enquanto nenhuma resposta do gênero masculino.

Essas respostas parecem confirmar o que Papalia (2006) descreve sobre os relacionamentos com a família, com os pares e com a sociedade adulta, pois os adolescentes passam uma quantidade de tempo cada vez maior com os amigos, mas os relacionamentos com os pais continuam sendo próximos e influentes. $O$ conflito com os pais tende a ser mais frequente durante a adolescência inicial e mais intenso na metade da adolescência. A criação democrática está associada com os resultados mais positivos.

Corroborando com essa argumentação, $\underline{\text { Coll, }}$ Marchesi e Palacios (2004) ressaltam que as relações com os pais exercem uma poderosa influência, por isso, uma alta coesão familiar e uma percepção positiva por parte de pais que demonstrem para seus filhos um alto grau de afeto e um controle democrático favorecem neles uma auto-avaliação positiva.

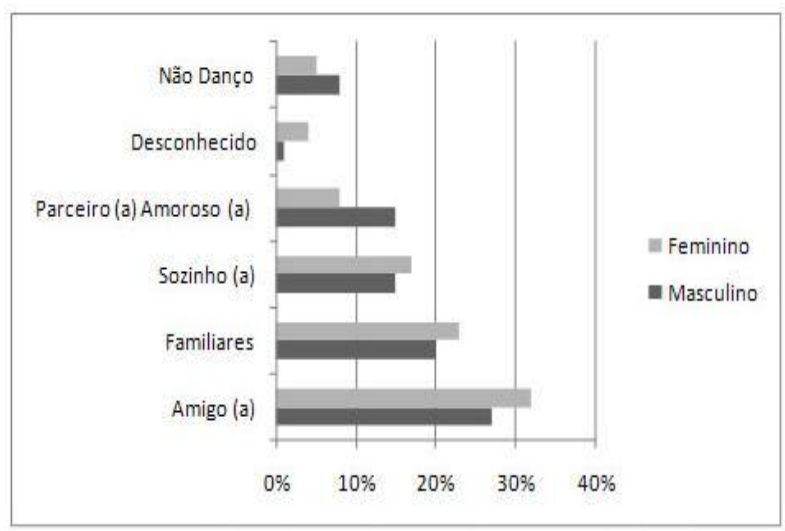

Figura 2. Com que os participantes costumam dançar nas festas. A somatória é maior do que $100 \%$ pela possibilidade de assinalar mais de uma alternativa.

Ao indagarmos sobre quais estilos-ritmos de dança os alunos geralmente dançam nesses lugares, 34\% dos participantes mencionaram dançar ritmos eletrônicos ("dance", "tecno", "house", etc); 26\% ritmos americanos ("country", "rock", "hip hop", "funk", etc); $22 \%$ ritmos brasileiros (samba, forró, axé, etc); $8 \%$ ritmos clássicos (bolero, valsa, tango, etc); $3 \%$ ritmos românticos (música lenta); $2 \%$ outros ritmos como o gospel e o contemporâneo e $5 \%$ da amostra disseram que não dançam. Não houve nenhuma diferença significativa entre as respostas entre o gênero feminino e masculino. Nessa questão os participantes poderiam marcar até três alternativas.

Através desses resultados podemos observar que os ritmos eletrônicos e americanos seguidos de ritmos brasileiros fazem parte do contexto social dos participantes desta pesquisa, contudo, os dois primeiros ritmos somados $(60 \%)$ estão mais presentes no cotidiano dos adolescentes, desfavorecendo o contato corporal proporcionado 
pelos ritmos brasileiros e clássicos (30\%), o que poderia auxiliar no processo de afetividade e no desenvolvimento emocional.

Diante do exposto, Campos (1982) enfatiza que são múltiplas as situações que despertam forte emoção entre os adolescentes, porque são pressionados a enfrentar e resolver problemas, jamais experimentados anteriormente. Assim, percebe-se que esta pode ser uma possível justificativa para a atitude negativa que tiveram muitos adolescentes em relação à proximidade corporal com o sexo oposto, o que parece ser evidenciado por uma imaturidade emocional para enfrentar situações dessa natureza.

Com relação ao motivo, ou seja, por que os participantes normalmente dançam: $53 \%$ relataram que é uma forma de entretenimento entendida como forma de lazer, diversão e descontração; $17 \%$ responderam que é o prazer de dançar, ou seja, a expressão como manifestação artística; $8 \%$ é uma maneira de gastar energia (como atividade física, sentir-se bem depois); $7 \%$ que é interação (socialização); $7 \%$ que permite um contato corporal (sensualidade) e $8 \%$ que não dançam.

Comparando-se os gêneros em relação a essa questão, os dados mais evidentes mostram que $48 \%$ do feminino dançam como forma de entretenimento enquanto $61 \%$ do masculino; $28 \%$ do gênero feminino dança pelo prazer de dançar enquanto apenas $1 \%$ do masculino e $3 \%$ do público feminino dançam devido à interação e socialização enquanto $11 \%$ do masculino.

Os achados mais relevantes da Figura 3 quanto à sensação percebida pelos alunos quando tiveram que dançar com os colegas revelam que $31 \%$ dos adolescentes tiveram uma experiência agradável, na qual argumentaram que a atividade de dança de salão foi legal/bem enquanto $33 \%$ tiveram uma sensação desagradável, onde demonstraram vergonha em dançar com o colega e outros consideraram a atividade ruim.

Nessa questão, as respostas foram praticamente semelhantes em relação ao gênero, divergindo somente em dois aspectos. No primeiro aspecto destacamos que os achados indicam que somente o público feminino (18\%) mencionou que a sensação percebida durante a atividade foi ruim (péssima/horrível). No segundo aspecto destacamos que $4 \%$ do feminino não dançaram com os colegas enquanto $11 \%$ do público masculino, dessa forma, os participantes não se manifestaram sobre essa questão.
No tocante a experiência agradável percebida pelos participantes em relação à atividade de dança de salão podemos relacioná-la com as emoções facilitadoras que de acordo com Adler e Towne (2002) contribuem para um funcionamento eficaz, pois sentir e expressar muitas emoções pode aumentar a qualidade dos relacionamentos interpessoais.

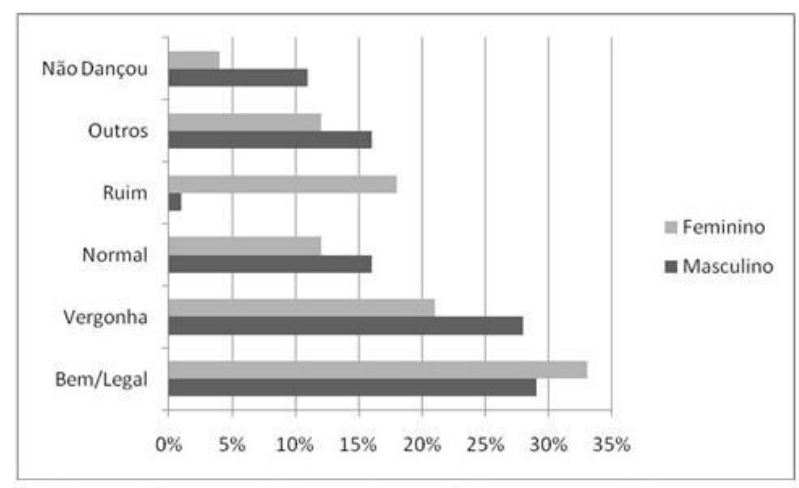

Figura 3. Sensação percebida pelo participante quando teve que dançar separadamente ou com o colega. A somatória é maior do que $100 \%$ pela possibilidade de assinalar mais de uma alternativa.

Em relação à sensação desagradável, parece que a vergonha apresentada pelos jovens pode estar relacionada à expressão emocional bem como de movimentos corporais indicativos de atitude desfavorável à aproximação. Adler e Towne (2002) caracterizam esses estados emocionais como debilitantes que nos impedem de sentir e de nos relacionar de um modo eficaz. Há várias razões pelas quais as pessoas não verbalizam muitas das emoções que sentem. As normas sociais, os papéis sociais e o medo das consequências de revelar algumas emoções levam as pessoas a se absterem de expressá-las.

Outro fator que também pode ter contribuído com esse receio em ter um contato corporal mais próximo com o colega, necessário para a prática da dança de salão, pode ser caracterizado pela invasão da zona íntima do outro, que geralmente utilizamos com pessoas que estão muito próximas em termos emocionais, principalmente em situações privadas e ao permitir que alguém avance para a nossa distância íntima, estamos permitindo que entre em nosso território (HALL, 1989). Cabe ressaltar que nessa dimensão as sensações negativas (ruim, péssimo, horrível) nas respostas apresentadas pelas meninas evidenciaram maior aversão ao contato corporal.

Adler e Towne (2002) apontam que o modo como partilhamos ou retemos nossos sentimentos de afeição pode afetar o futuro de nossos relacionamentos, dessa forma, a comunicação 
molda nossos sentimentos, e os sentimentos influenciam a comunicação. O sucesso de uma pessoa no mundo depende em grande parte da capacidade de compreender e de administrar as próprias emoções e ser sensível aos sentimentos dos outros.

Volp (1994) em sua tese argumenta que talvez os jovens demonstrem certo receio ao contato corporal (o tocar e o dançar de rosto colado) devido às questões corporais estarem em evidência em decorrência do seu desenvolvimento sexual e físico, ou às emoções que se manifestam descontroladamente quando o corpo é tocado, admirado, reconhecido, ou simplesmente, esse receio seja a resposta juvenil à pressão adulta da manifestação sexual, criando problemas onde eles não existem.

O toque segundo Volp (1994), nesse jogo dançante, estabelece a comunicação mais íntima entre os pares. Naturalmente, aqueles que não querem se envolver, não tocam e não percebem o toque como canal de emissão de mensagens. São capazes até de dançar sem se tocar.

Complementando a análise dessa questão através da observação da filmagem, nota-se que a comportamento territorial entre os participantes ficou mais distante que a recomendada pelos códigos existentes na prática da dança de salão, mesmo por aqueles participantes que aceitaram dançar com o colega. Volp (1994) esclarece que o contato corporal na dança de salão obedece às regras sociais, reforçando-as.

A próxima indagação tinha como finalidade saber a opinião dos participantes quanto à importância de saber dançar: 73\% mencionaram que é importante saber dançar; $20 \%$ disseram que agora não, mas no futuro sim; $5 \%$ disseram que não é importante saber dançar e $2 \%$ descreveram que mais ou menos.

Comparativamente, os dados mais relevantes nos mostram que $29 \%$ do público feminino não consideram importante saber dançar agora, mas no futuro sim enquanto $7 \%$ das respostas masculinas; $11 \%$ do gênero masculino responderam que não é importante saber dançar em nenhum momento enquanto não obtivemos nenhuma resposta feminina e $6 \%$ do gênero masculino não tem uma opinião formada, pois descreveram que mais ou menos, porque não gosta de dançar muito.

Dentre as respostas dos participantes que afirmaram ser importante saber dançar elencamos algumas justificavas apresentadas por participantes masculinos $(M)$ e femininos $(F)$ :

Porque se um dia alguém me chamar para dançar numa festa, eu vou dançar! (M4).
Para ter maior entrosamento com a sociedade e com as garotas (M15).

Porque dançar é se divertir e eu tenho prazer de dançar eu me sinto bem, eu esqueço de problemas que eu tenho em casa ou em outros lugares. $E$ vou sempre dançar até no futuro pois eu gosto e eu me sinto livre (F9).

Pois quando você precisar dançar em seu casamento, festas, bailes, você já vai saber dançar, assim ficará mais fácil (F22).

Analisando esses resultados percebe-se que os participantes mencionaram os inúmeros benefícios que a dança, especificamente neste estudo a dança de salão, pode proporcionar aos indivíduos e os mais variados motivos para a importância de saber dançar.

Contribuindo com essas respostas, Volp (1994) ressalta que a dança de salão possui muitos aspectos positivos para quem a pratica, entre eles estão o envolvimento com ambos os processos, tanto físicos como mentais; aquisição de habilidades físicas e intelectuais; desenvolvimento do "eu" e o melhoramento do auto-conceito, autoestima e identidade através do uso de movimentos corporais; integração dos aspectos mentais, físicos, emocionais e espirituais.

A autora ainda enfatiza que a dança de salão fornece condições que possibilita dar confiança ao indivíduo e ao grupo, o que resulta na formação de um cidadão melhor preparado para lidar com seu ambiente e confiante para contribuir com a comunidade; conhecimento de si mesmo pela participação no processo criativo, como também melhoria da postura, possibilitando ainda emagrecer, fortalecer o coração e músculos e diminuir o estresse.

Os resultados referentes a qual ritmo os participantes masculinos e femininos consideraram mais fácil nesta vivência de dança de salão: $38 \%$ responderam que o ritmo mais fácil foi a valsa; $30 \%$ o forró; $14 \%$ não sentiram dificuldades e acharam os dois ritmos fáceis; $5 \%$ não consideraram nenhum ritmo fácil; $5 \%$ não mencionaram qual dos ritmos considerou fácil e $3 \%$ não dançaram junto com o parceiro.

Os dados revelaram que houve discordância entre os gêneros em relação qual ritmo foi mais fácil durante a atividade de dança de salão. Para o gênero masculino, o ritmo mais fácil foi à valsa com $61 \%$ dos participantes enquanto que para $46 \%$ do gênero feminino foi o forró. Para $21 \%$ do público feminino os dois ritmos, ou seja, tanto a valsa quanto 0 forró foram fáceis enquanto somente $6 \%$ do masculino. Para $11 \%$ do público masculino, nenhum ritmo foi fácil enquanto não tivemos resposta feminina. E $8 \%$ do público feminino não informaram qual ritmo foi mais fácil 
aprender, pois não mencionou nem deu explicações enquanto não tivemos respostas masculinas.

$\mathrm{Na}$ opinião dos participantes (38\%), a valsa foi o ritmo mais fácil de ser dançado, apesar da maioria não ter vivência com aulas de dança de salão. Esse fato pode ter ocorrido porque nesta aula foi ensinado somente o passo básico de cada ritmo, o que possibilitou um maior envolvimento dos sujeitos na primeira parte da aula em que eles aprendiam os passos individualmente. Porém quando solicitava a formação dos pares para executar os movimentos com o parceiro do sexo oposto, os participantes tinham dificuldades em estabelecer uma maior proximidade, ou seja, de encontrar uma distância confortável para dançar, já que a professora ensinava a distância correta para ficar com 0 parceiro em cada ritmo.

Contudo, os participantes desempenharam-se melhor na valsa do que no forró. Uma possível justificativa pode estar relacionada com os comportamentos territoriais, pois na valsa a proximidade entre os participantes é um pouco mais distante do que no forró, o que permitia de certa forma uma distância considerável entre os parceiros. Já no forró esse espaço informal é muito próximo, exigindo um contato corporal total entre os indivíduos, bem como uma intimidade maior entre eles, causando um desconforto no momento de dançar. No caso da dança de salão, o contato físico é considerado como um espaço informal íntimo, onde o contato corporal torna-se real.

Outra justificativa pode estar relacionada ao fato do forró exigir uma maior soltura de quadril, na qual o gênero masculino sente dificuldades e não se sente tão à vontade para executar tal movimento quanto o feminino. Notamos ainda que o fator cultural a respeito do machismo exerce uma influência muito grande nos padrões de comportamento desses participantes, apesar de evidenciarmos uma ligeira ruptura desses preconceitos em relação ao homem dançar e principalmente rebolar, notou-se que nesse universo os adolescentes masculinos apresentaram-se inibidos quando solicitados para dançar com uma soltura maior de quadril.

\section{Considerações}

Através dos resultados verificou-se que os tipos de festas que os participantes frequentam não propiciam um contato corporal necessário e exigido pelos ritmos de dança de salão. Geralmente os participantes costumam dançar às vezes e dançam principalmente com amigos, familiares e sozinhos, o que demonstra que tem mais intimidade em dançar com pessoas próximas ao círculo familiar.

Nota-se que a vivência dançante dos adolescentes e os estilos-ritmos de dança que eles geralmente dançam nas festas restringiram a participação deles na aula de dança de salão, talvez, se os participantes tivessem maior contato com vários ritmos de dança durante o processo escolar desde os primeiros anos escolares, teria uma maior participação e uma melhor qualidade da interação social, pois essas vivências dançantes fariam parte de um processo gradual, onde poderia ocorrer um fortalecimento das relações interpessoais. Nesse contexto, a dança de salão, no conceito de Gonzaga (1996), além de ser uma atividade física que influencia na formação da estrutura corporal, também auxilia no fator da socialização, facilita a aproximação e toque em outros indivíduos.

Pretendeu-se nesta pesquisa oportunizar aos participantes uma vivência dançante através da dança de salão na própria escola e durante a aula de educação física. Contudo, observamos que houve certa resistência por alguns alunos pela novidade, o que é totalmente normal, uma vez que tudo que é novo causa estranheza, porém acreditamos que se os participantes tivessem mais oportunidades de participarem desse tipo de atividade os resultados poderiam ser melhores e diminuiria a intimidação sentida pelos adolescentes de se aproximar e de demonstrar afetividade para com os colegas.

Corroborando com os achados deste estudo sobre a sensação percebida pelos adolescentes no ato de dançar, Bregolato (2000) ressalta que a dança de salão, aproxima os alunos, e vem colaborar para diminuir o preconceito do toque corporal que está explícito na sociedade, o que torna os sujeitos distantes e maliciosos. A dança de salão por proporcionar a condição do toque em situação de respeito, possibilita a socialização dos indivíduos condicionando a aproximação para amizades e o contato corporal do indivíduo.

Os participantes consideram a dança importante de acordo com os relatos coletados e podemos inferir que os adolescentes de uma forma geral sabem que dançar permite uma gama de possibilidades e significados/sentidos. Neste sentido, Rocha e Almeida (2007) constataram que a dança de salão tem um grande potencial educativo, já que o seu próprio aprendizado leva a utilização do movimento para expressar idéias, sentimentos, emoções, pensamentos, ou ainda, princípios filosóficos, sociais ou políticos. Mais ainda: em decorrência de sua essência integradora dos domínios humanos é capaz de levar a pessoa descobrir e/ ou redescobrir sua 
corporeidade e sensibilidade. A simples observação da prática de dança de salão leva a percepção de quão rica é em expressões não verbais, a ponto de ser necessário buscar subsídios na forma mais pura da linguagem oral e escrita para entender e descrever a linguagem do corpo que dança, do corpo que fala.

No que se refere ao universo investigado podemos destacar que as danças ocorrem em baladas e festas no círculo familiar, onde a maioria destes jovens dança ao som de músicas eletrônicas, geralmente dançam sozinhos ou em pequenos grupos, mas sempre individualmente.

Podemos inferir que existem poucas oportunidades de vivenciar os ritmos de dança de salão tanto no ambiente familiar quanto escolar, não permitindo dessa forma um relacionamento mais próximo entre os adolescentes, o que prejudica o contato corporal e que poderia contribuir para comportamentos como respeito, demonstração de afeto, companheirismo, melhora da autoestima, da confiança, bem como a possibilidade de melhorar as relações interpessoais do grupo.

Através deste estudo, espera-se poder contribuir para que os profissionais ligados ao conteúdo de dança na escola, ressaltando a importância que essa discussão promove a todos os professores de Educação Física escolar, independente de serem especialistas em dança, para que comecem a pensar nesse conteúdo, para que por meio dele possam discutir e refletir sobre os benefícios que tal conteúdo representa na vida dos alunos, bem como saber o que os alunos eventualmente pensam a respeito dessa questão e principalmente como se sentem realizando uma atividade dançante.

Embora não seja nossa pretensão esgotar o assunto, esperamos que as reflexões deste estudo ressaltem a importância de oportunizar para os alunos mais atividades dançantes como a dança de salão, possibilitando o máximo de vivências corporais, e assim melhorar a qualidade de vida em todos os aspectos (física, cognitiva e afetiva) por meio de uma prática lúdica, divertida e prazerosa.

\section{Referências}

ADLER, R. B.; TOWNE, N. Comunicação interpessoal. Rio de Janeiro: LTC, 2002.

ABERASTURY, A.; KNOBEL, M. Adolescência normal: um enfoque psicanalítico. Porto Alegre: Artes Médicas, 1981.

BEE, H. A criança em desenvolvimento. Porto Alegre: Artmed, 2003.
BREGOLATO, R. A. Cultura corporal da dança. São Paulo: Ícone, 2000. v. 1.

CAMPOS, D. M. S. Psicologia da adolescência: normalidade e psicopatologia. Petrópolis: Vozes, 1982.

COLL, C.; MARCHESI, A.; PALACIOS, J. Desenvolvimento psicológico e educação. Porto Alegre: Artmed, 2004.

CONTINI, M. de L. J.; KOLLER, S. H.; BARROS, M. N. S. Adolescência e psicologia: concepções, práticas e reflexões críticas. Rio de Janeiro: Conselho Federal de Psicologia, 2002.

DEUTSCH, S. Musica e dança de salão: interferências da audição e da dança nos estados de animo. 1997. 165f. Tese (Doutorado em Psicologia Experimental) - Psicologia, Departamento de Instituto de Psicologia, Universidade de São Paulo, São Paulo, 1997.

FREITAS, R.; BARBOSA, C. Danças de salão, a vida em movimento. Franca: Fundação Mário de Andrade, 1998.

GONÇALVEZ, N. L. G. Metodologia do ensino da educação física. Cutiriba: Ibpes, 2006.

GONZAGA, L. Técnicas de dança de salão. Rio de Janeiro: Sprint, 1996.

HALL, E. T. A dimensão oculta. Rio de Janeiro: Francisco Alves, 1989.

KNAPP, M. L.; HALL, J. A comunicação nãoverbal na interação humana. São Paulo: JSN, 1999.

MONTAGU, A. Tocar: o significado humano da pele. São Paulo: Summus, 1988.

NANNI, D. Dança-educação: pré-escola à universidade. Rio de Janeiro: Sprint, 1995.

PAPALIA, D. E. Desenvolvimento humano. Porto Alegre: Artmed, 2006.

PEASE, A.; PEASE, B. Desvendando os segredos da linguagem corporal. Rio de Janeiro: Sextante, 2005.

PEREIRA, M. L. A formação acadêmica do professor de educação física: em questão o conteúdo da dança. 2007. 187f. Dissertação (Mestrado em Ciências da Motricidade) - Instituto de Biociências, Universidade Estadual Paulista, Rio Claro, 2007.

RIED, B. Fundamentos de dança de salão: programa internacional de dança de salão. Londrina: Midiograf, 2003. 
ROCHA, M. D.; ALMEIDA, C. M. Dança de salão, instrumento para qualidade de vida. Movimento \& Percepção, Espírito Santo de Pinhal, v. 7, n. 10, jan./jun. 2007. Disponível em:

$<$ http://www.efmuzambinho.org.br/refelnet/index1. asp?codrevista $=180 \&$ issn $2=\&$ titulo=Movimento\#e dicoes>. Acesso em: 18 jan. 2010.

SHAFFER, D. Psicologia do desenvolvimento: infância e adolescência. São Paulo: Pioneira:

Thomson Learning, 2005.

VOLP, C. M. Vivenciando a dança de salão na escola. 1994. 275f. Tese (Doutorado em Psicologia Escolar) - Psicologia, Departamento de Instituto de Psicologia, Universidade de São Paulo, São Paulo, 1994.

VOLP, C. M. A dança de salão como um dos conteúdos de dança na escola. Motriz, Rio Claro, v. 16, n. 1, p. 215-220, jan./mar. 2010. Disponível em:

$<$ http://www.periodicos.rc.biblioteca.unesp.br/inde x.php/motriz/article/view/3397/2887>. Acesso em: 10 fev. 2010

VOLP, C. M.; DEUTSCH, S.; SCHWARTZ, G. M. Por que dançar?: um estudo comparativo. Motriz, Rio Claro, v. 1, n. 1, p. 52-58, jun. 1995.

Disponível em:

$<$ http://www.periodicos.rc.biblioteca.unesp.br/inde x.php/motriz/article/view/962/892>. Acesso em: 25 nov. 2009

\section{Endereço:}

Nilza Coqueiro Pires de Sousa

R. Capitão Alcides, 20-17, Bloco A - Apto 32

Jardim Paulistano

Bauru SP Brasil

17030-510

Telefone/Fax: (14) 3203.2352 e 9773.5133

e-mail:ncoqueiro@itelefonica.com.br

Recebido em: 30 de setembro de 2010.

Aceito em: 20 de abril de 2011. 